\title{
ENTREVISTA COM JULIANE HOUSE ${ }^{1}$
}

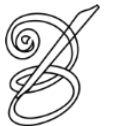 \\ Cristiane Roscoe Bessa \\ (LET/UnB) \\ crbessa@unb.br \\ Julio César Neves Monteiro \\ (LET/UnB) \\ cesarj1@gmail.com \\ Alessandra Ramos de Oliveira Harden \\ (LET/UnB) \\ oliveira.ales@gmail.com \\ Flávia Arraes Lamberti \\ (LET/UnB) \\ flavialamberti@gmail.com
}

om mais de duzentos trabalhos publicados (25 livros) desde a década de 1970, Juliane House, professora emérita da Universidade de Hamburgo, é dona de um currículo invejável. Dele constam resultados de pesquisas para as quais convergem os vários interesses de House: tradução, linguística funcional, comunicação interlinguística e intercultural, contato linguístico, análise textual, ensino de língua estrangeira, pragmática e outros. A curiosidade e o espírito investigador dessa pesquisadora incansável parecem levá-la sempre por caminhos definidos por sua imensa paixão pelos mistérios da linguagem e das relações entre as línguas. Uma de suas principais colaborações para a área de tradução foi a elaboração de um modelo para a avaliação de traduções com base nos conceitos da linguística sistêmico-funcional (ver seção de bibliografia selecionada). Em visita à Universidade de Brasília para uma série de eventos, em novembro de 2011, House concedeu a breve entrevista reproduzida abaixo.

A chamada virada cultural dos estudos da tradução foi, para muitos, uma espécie de libertação da linguística. A senhora acha que isso condena seu modelo a certo ostracismo dentro da área? 
JULIANE HOUSE: De jeito nenhum. Meu objetivo, meu modelo, é basicamente linguístico, mas, por causa da noção de filtro cultural que lhe é inerente, é também de grande relevância para se pensar as questões culturais. Além disso, de maneira geral, discordo totalmente dos que afirmam que a virada cultural tenha nos liberado da linguística. Como é possível fazer qualquer coisa na área de tradução sem ao menos uma noção de linguística ou sem levar em conta a língua? Afinal, quando lidamos com tradução, estamos lidando com textos, com discursos. Então, claro que precisamos da linguística. Se nosso trabalho não estiver embasado na linguística, acabamos apenas com afirmações vagas do tipo "esse aspecto é relevante para a cultura de chegada" ou coisa assim. A relação com a linguística, quero enfatizar, é o que torna nossa área de estudo mais respeitável e mais científica.

É mesmo razoável esperar que um modelo ou abordagem sistemática se mostre capaz de lidar com todas as complexidades da tradução e do processo tradutório?

JH: Acredito que sim, por que não? Por que pensar que a tradução é assim, tão terrivelmente complexa? Se você vai traduzir um texto, tente se informar sobre a microssituação de sua produção e recepção. Via de regra, o tradutor sabe quem escreveu o texto, quem vai receber a tradução, o momento histórico e o local em que esse texto foi escrito. Pode, portanto, descrever bem sua microssituação. Pode ser mais difícil examinar o contexto macrocultural. Nesse aspecto, há uma carência de descrições cruzadas, por exemplo, que se dediquem às diferenças entre a cultura brasileira e as culturas hispânicas na América do Sul. Há dificuldades, mas é possível pelo menos tentar produzir uma descrição que será resumida no texto, de dimensões de divergências em termos de convenções textuais, de expectativas do público-alvo. Isso pode ser feito com auxílio da literatura existente. Se há uma limitação, ela é decorrente dos limites do nosso conhecimento, o que não significa que o modelo que proponho seja inútil porque pressupõe que saibamos tudo. Isso não é verdade, o modelo não é construído nessa base. Devemos tentar capturar essas diferenças, e o modelo captura muita coisa.

Uma tradução é um texto. Substitui, supostamente, o original, ou seja, segue seu caminho desacompanhado do original. O público-alvo determina o encargo da tradução (translation brief) isso enfraquece o duplo vínculo (double bind) no qual a senhora insiste?

Meu modelo não prevê o encargo da tradução. Quem trabalha com o encargo da tradução não precisa de um modelo. A teoria do escopo só tem sentido se baseada no encargo da tradução. Alguém diz para o tradutor: "produza, da forma mais eficiente possível, um texto 
que esteja o mais próximo possível de um texto na cultura fonte", o que me parece muito vago. Eu, no entanto, tento, com o modelo, descobrir o que o texto original fez em seu cenário original e determinar, com base no que eu posso interpretar desse texto, como ele deveria ser traduzido. Há algo na noção de encargo da tradução que não me convence, porque não limita ou especifica o que um tradutor pode fazer. Como eu disse antes, quem usa o encargo de tradução não precisa do modelo. Ou talvez fosse o caso de combinar o encargo da tradução e o modelo, o que é possível, mas eu não tentei.

Qual a sua opinião sobre a abordagem de Mona Baker, ${ }^{2}$ que está tão voltada para questões de poder, ética e conflito na tradução?

JH: Eu não diria que Baker tem uma abordagem específica. Nos últimos anos, ela vem trabalhando muito sobre ética e conflito, por causa de seu comprometimento político, que é muito forte e louvável. Ela está envolvida com questões relativas à crise e comunicação também, mas começou sua carreira como linguista. A segunda edição do seu In other words ${ }^{3}$ está muito voltada para a linguística, mais especificamente para a linguística funcional. O que Baker ainda não fez foi vincular suas duas áreas de interesse. Quando fala sobre ética e conflito, ela não usa o enfoque que temos em In other words. Muitas pessoas perguntam o que a abordagem de Baker tem a ver com tradução. Tem muito a ver. Aliás, a minha crítica às abordagens pós-modernas e desconstrucionistas e mesmo à análise crítica do discurso, de Fairclough $^{4}$ e outros, é que eles não fazem o trabalho de base, que é linguístico. Eles começam afirmando que um texto é colonial ou racista, por exemplo, se o texto traduzido glorifica Colombo ou a descoberta da América do Sul. Dizem que o tradutor não deveria glorificar Colombo, nem mesmo dar nome a ele e mencioná-lo apenas como navegador. Esse posicionamento deve ser apoiado em análise linguística detalhada. O que ocorre, porém, é que os adeptos dessas abordagens realizam análises linguísticas superficiais, devido a seu engajamento. Eu não diria que Baker faz isso, mas seria ótimo se ela unisse seus dois principais interesses de pesquisa.

A senhora acha que somente uma abordagem linguística da tradução pode ser considerada científica?

JH: No momento, creio que sim. Talvez seja ignorância de minha parte, mas eu não vejo muita sistematicidade na abordagem cultural. Claro, é preciso definir o que é "científico". Para mim, significa mostrar da forma mais transparente possível o que o tradutor está fazendo com o texto. Apresentar razões que justifiquem o que está sendo feito. No caso de avaliação 
de traduções, apresentar as razões do percurso analítico seguido. Isso não quer dizer que a tradução de textos literários seria menos científica. É possível fazer uma análise linguística minuciosa do texto literário; isso já foi feito, por exemplo, por Michael Halliday, que analisou poemas com base nos registros. Christian Matthiessen, colaborador de Halliday, ${ }^{5}$ também aplicou essa abordagem aos textos literários. Mas é uma abordagem linguística, claro. Talvez a questão devesse ser reformulada: seria essa a única abordagem válida? Bem, é a única que se presta mais obviamente para a tradução, porque a tradução é sempre uma operação entre línguas, não se pode fugir disso. O que mais temos, o que as pessoas que trabalham no contexto da chamada virada cultural fazem com os textos? Parece-me que fazem uma análise individual. Sei que há pessoas no Brasil que usam a noção de antropofagia. É uma hipótese muito interessante, mas não é uma teoria. Uma teoria é um conjunto de hipóteses, um sistema fechado, e é disso que precisamos na tradução. Correndo o risco de parecer imodesta, posso afirmar que o meu modelo é o único que é fechado. Talvez tenhamos outros melhores no futuro, mas, hoje, meu modelo está definido de forma apropriada, é um sistema, é transparente, é descritivo e é explicativo.

A senhora diria que a tradução literária é menos científica do que - ou tão científica quanto - a tradução de qualquer outro tipo de texto?

Claro, depende se a tradução em análise tem fins práticos. Se o objetivo for descrevêla, podemos usar meu modelo ou qualquer outro modelo de modo a analisar a tradução cientificamente. $\mathrm{O}$ ato de traduzir em si não é uma ciência, é uma atividade muito prática. Mas o que é feito com a tradução, como ela é descrita, como ela é explicada, é aí que a ciência entra. Não importa a natureza do texto a ser traduzido, se é uma propaganda boba, um slogan ou o rótulo em uma embalagem de papel higiênico. Todos podem ser descritos cientificamente. Poemas também podem ser descritos de forma científica.

Como o seu modelo pode suprir as necessidades de um programa de formação de tradutores?

JH: Margherita Ulrych ${ }^{6}$ compara a formação de tradutores à formação de médicos, que são treinados para serem capazes de diagnosticar uma doença, ou seja, torná-la transparente por meio do diagnóstico. É isso que precisamos fazer nos cursos de tradutores. Meu modelo pode ajudar a sensibilizar os alunos quanto à natureza da linguagem, da produção textual e quanto às similaridades de certos textos ou gêneros textuais. Se usarmos como exemplo cartas escritas para acionistas de uma empresa, o interessante seria revelar, com ferramentas linguísticas, como esses textos se assemelham em línguas diferentes e em que ponto eles se 
diferenciam. O principal é que nos afastemos da noção relativamente primitiva de um tipo textual como expressivo, informativo ou apelativo, que eu acho simplista demais. Em outras palavras, precisamos sensibilizar os alunos no sentido de mostrar-lhes o que pode ser feito com a língua, mostrar-lhes a beleza da linguagem. Para isso, claro, é preciso que usem a metalinguagem: precisam conhecer termos com os quais possam descrever o que estão fazendo quando analisam um texto. Precisam saber como diferenciar um verbo de um substantivo, como construir períodos complexos, como combinar uma oração com outra, como usar conectores ou repetição lexical, por exemplo. Todas essas coisas são como blocos de montar da análise. Os alunos devem ser capazes de realizar uma análise, e, para esse fim, meu modelo pode ser simplificado, se os professores o considerarem complicado demais para os alunos. Em uma análise que considere as relações entre os participantes (tenor), ${ }^{7}$ por exemplo, o que importa são os tipos de adjetivos usados para descrever a emocionalidade de um texto. Quantos pronomes há no texto? São pronomes pessoais ou não? O nível estilístico é formal ou não? Todos podem chegar a esse nível de análise. Para o elemento modo, a pergunta seria: esse texto é mesmo um texto escrito ou fica entre o escrito e o oral? O bom é

que o modelo oferece aos alunos um esquema de categorias que facilita as coisas, já que eles poderiam ficar perdidos em meio a uma multiplicidade de fatos isolados. A vantagem de uma teoria ou de um modelo é justamente essa facilitar as coisas. Uma boa teoria é prática, porque diminui a confusão. Qualquer aluno no início da vida universitária sabe disso. A ideia é deixar as coisas mais simples. Isso parece um contrassenso, porque as pessoas pensam "ai, teoria, tão difícil, não vou conseguir", mas, na verdade, as coisas ficam mais concretas.

\section{ALGUNS TRABALHOS DE JULIANE HOUSE}

HOUSE, Juliane. A model for translation quality assessment. Tübingen: Narr, 1977.

The Evaluation of translations. In: The encyclopedia of language and linguistics. London: Pergamon Press, 1993. p. 4700-4708.

Quality of translation. In: BAKER, M. (Ed.). Encyclopedia of translation studies. London: Routledge, 1997. p. 197-200.

Concepts and methods of translation criticism: a linguistic perspective. Hamburg: Arbeiten zur Mehrsprachigkeit: 2000.

How do we know when a translation is good? In: STEINER, E.; YALLOP, C. (Ed.). Exploring translation and multilingual text production: beyond content. Berlin: Mouton de Gruyter, 2001. p. 127-160. 
Pragmatics of translation. In: NISTAL, P. F.; BRAVO GOZALO, J.M. (Ed.). Pathways of translation. Valladolid: Cuentro Buendia, 2001. p. 57-79.

Universality versus culture specificity in translation. In: RICCARDI, A. (Ed.). Translation Studies: perspectives on an emerging discipline. Cambridge: Cambridge University Press, 2002. p. 92-111.

Translation. Oxford: Oxford University Press, 2009.

Overt and covert translation. In: GAMBIER, Y.; DOORSLAER, L. van (Ed.). Handbook of translation studies, vol. 1. Amsterdam: Benjamins, 2010. p. 245-246.

Translation, interpreting and intercultural Communication. In: JACKSON, J. (Ed.). Routledge Handbook of Intercultural Communication. London: Routledge, 2011. p. 495509.

. Quality in Translation and Interpreting Studies. In: MILLAN-VARELA, C.; BARTRINA, F. (Ed.). Routledge Handbook of Translation Studies. London: Routledge, 2012.

Translation Quality Assessment: linguistic description versus social evaluation. Meta: Translators' Jounal, v. 46, n. 2, p. 243-257, jun. 2001. Disponível em: <http://www.erudit.org/revue/meta/2001/v/n2/003141ar.html>. Acesso em: 25 maio 2012.

${ }^{1}$ Entrevista concedida em inglês a Cristiane Roscoe Bessa e Julio César Neves Monteiro; tradução, edição e notas: Alessandra Ramos de Oliveira Harden Flávia Arraes Lamberti.

2 A teórica Mona Baker tem se dedicado, nos últimos anos, ao estudo da tradução em áreas de conflito, especialmente no Oriente Médio. Seus trabalhos nesse campo de pesquisa podem ser encontrados no site www.monabaker.com.

${ }^{3}$ BAKER, M. In other words: a coursebook on translation. London: Routledge, 2011.

${ }^{4}$ Ver, por exemplo: Norman Fairclough. Discurso e mudança social. Coord. Trad., revisão e prefácio à edição brasileira Izabel Magalhães. Brasília: Editora da Universidade de Brasília, 2001.

${ }^{5}$ Ver HALLIDAY, M.A.K.; MATTHIESSEN, C.M.I.M.. An introduction to functional grammar. $3^{\text {rd }}$. ed. London: Arnold, 2004.

${ }^{6}$ Professora na Università Cattolica Del Sacro Cuore, na Facoltà di scienze linguistiche e letterature straniere, em Milão.

${ }^{7} \mathrm{O}$ modelo de House é baseado nos conceitos da gramática sistêmico-funcional de Halliday, motivo pelo qual a autora utiliza os termos field, tenor e mode, seguindo o exemplo de Halliday. Por isso, a tradução de tenor como "relações entre os participantes", embora possam ser encontradas, na literatura da área, também as traduções "relações" e "relações interpessoais". Field e mode são tradicionalmente traduzidos como "campo" e "modo". 